\title{
Multifactorial Assessment of Monopolisation Trends through the Analytical Prism of Price-Based Market Power and Business Cycle Fluctuation Quantitative Evaluation
}

\author{
Maija Senfelde, Dmitrijs Skoruks, Jekaterina Nazarova
}

Riga Technical University

Kalku st. 1, Riga, Latvia

E-mail.Maija.Senfelde@rtu.lv,Dmitry.Skoruk@gmail.com,Catherine.Nazarova@gmail.com

cross $^{\text {ref }}$ http://dx.doi.org/10.5755/j01.ee.27.5.14921

\begin{abstract}
The research "Multifactorial Assessment of Monopolisation Trends through the Analytical Prism of Price-Based Market Power and Business Cycle Fluctuation Quantitative Evaluation" provides a multi-perspective in-depth analysis of the nature, the occurrence sources, the development features and the conjuncture specifics of the modern process of monopolisation, assessed through the prism of coherent and multifactorial econometrical modelling. The main scope of the aforementioned research is devoted to further developing and significantly enhancing the previously introduced monopolisation trend quantitative analysis methodologies, developed by Skoruks, Nazarova and Šenfelde, (Skoruks et al, 2015a,b,c) through simultaneous consideration of the broader context of price volatility and the relevant external factors, existing at various stages of business cycle spiral development, which affect the conduct of internal economic processes within a defined relevant market. The conducted research provides an example of modern econometrical method application within a unified framework of market competition environment analysis for the purpose of conducting a quantitative monopolisation trend evaluation on a relevant market level, while simultaneously considering the business cycles-induced effects on pricing strategies, implemented by the supply-side market actors. The research results may be defined as a system of complex outcomes, which enable the taking of the next constituent step in monopolisation trend detecting, quantification and evaluation, while simultaneously developing an innovative indicator, which had proven to be highly complementary with, while remaining functionally independent of, the analytical systems, used in previously developed methodologies, thus creating a positive synergetic effect in terms of enhancing the functionality, implementation efficiency and outcome transparency of the conducted empirical research.
\end{abstract}

Keywords: Monopolisation, Business Cycle, Relevant Market, Market Power, Competition.

\section{Introduction}

The modern economic theory as any dynamic and constantly developing scientific field had undergone and still finds itself engaged in a series of productive discussions on various topics, ranging from microeconomic incrementalism of industrial organisation (Tirole, 1988) to international outlook of innovation-based inclusive macroeconomic growth (Daude et al., 2016), which elaborate, enhance and occasionally question the established conformity of existing research paradigms. With the vast development of business practices and the advent of the globalised system of international trade, numerous formerly unquestioned and unchallenged visions of the economy functioning principles, market mechanisms and causality of business conduction processes had already been and still find themselves in a stage of productive transformation, re-evaluation and positivelycritical analysis from various scholarly as well as professional perspectives. (Skoruks \& Senfelde 2015) Based on Adam Smith's classic theory (Smith, 2007), John Maynard Keynes alternative approach (Keynes, 2011) and works of Paul Samuelson (Samuelson, 1939), economic research is continuously developing along with the endlessly flexible social and entrepreneurial agenda, causally following and quickly reacting to newly emerging global and regional challenges. While considering the research, conducted by some of the most notable scholars of empirical economic theory (Chamberlin, 2010; Keynes, 2011; Robinson, 2012; Samuelson, 1939; Tirole, 1988), one may reasonably argue that certain aspects of market interactions are justly deemed fundamental and thus should not be subjected to any sort of revisionary agendas, which occasionally do find their way onto the discussion topic lists of the modern economist community.

Without prejudice to acknowledging certain areas of economic analysis, such as the demand-supply based market equilibrium or the law of diminishing returns, as indubitably empirical, a certain area of market functioning is indeed being addressed diversely by various scholars, professionals and interest group representatives due to the structural controversy, imbedded in the very essence of the relevant phenomenon. The issue in point is the process of monopolisation, occurring in an open market economy and seemingly contradicting both the economic reasoning for competition-bases resource utilization, variating product distribution paradigms as well as means of production allocation and the core benefit to society, brought by consumer choice possibilities, namely, need satisfaction in the context of market functioning efficiency.

The objective of the current research is to conduct a multifactorial study of monopolisation process development through the prism of quantitative econometrical analysis, while considering the specifics of market power distribution, 
the volatility of medial market prices and the broader context of business cycle fluctuations as well as the constituent interrelatedness of the mentioned parameters.

The hypothesis of the current research may be defined as follows: monopolisation trends in modern open market economies are driven by excessive individual market power concentration, hence they may be detected and quantitatively measured by evaluating a defined competition environment through analysis of the relevant price levels, while taking into account the possible differences in generated quantitative results qualitative interpretations, depending on the broader macroeconomic conditions, reflected by shifting between various stages of the empirical international business cycle.

The scientific object of the current research may be defined as market power, perceived as an economic phenomenon, which is affected by both internal and external conjuncture qualities of the analysed competitive environment, namely, the medial market price and the maturity/development level of the relevant business cycle.

The following assessment methods had been used in order to conduct the current research: monographic analysis, econometrical modelling, mathematical criteria analysis, quantitative economic pattern analysis, qualitative indicator value range construction and consequential input data analysis.

\section{Theoretical Background and Scientific Justification of the Conducted Research}

As it had been previously argued, while the presence of a truly full monopoly undoubtedly brings unrecoverable (deadweight) losses to the society, the process of monopolisation is a natural state of affairs, based on both resource limitations and enterprise struggle for profitability, with the mentioned tendencies becoming excessively persistent and particularly visible in times of economic downslide and external shock occurrence. (Skoruks, 2014)

The first deviation from the situation of competition, sufficient in terms of intensity and efficiency, is the obtaining of a dominant market position, which is recognized by the European Union Competition Law as not an infringement per se but rather as a potentially risky situation of possible future negative market trend development. As defined in the Article 102 of the Treaty on the Functioning of the European Union, "any abuse by one or more undertakings of a dominant position within the common market or in a substantial part of it shall be prohibited as incompatible with the common market insofar as it may affect trade between Member States". (TFEU, 1958) Therefore, it may be concluded that monopolisation trends constitute a potentially negative economic development, however, in certain situation, such state of affairs may be "the least of two evils" in regards to the only remaining economically efficient option being a public body interference or even nationalisation, the latter being highly incompliant with the current developments in and the founding legislation of the Single European market. (Stucke, 2007; Council of the European Union, 2003)

The question arises in defining the limits of monopolisation process remaining an economically natural and, in terms of market functioning efficiency, mostly tolerable development due to the fact that reasonable market consolidation is an ineluctable counterpart of efficient and productive competition, while taking into account those interpretational differences, which are present due to the specifics of the relevant stage of the macroeconomic business cycle development that markets hind themselves operating in.

A vast variety of singularised methods of monopolisation level assessment currently exists and certain methods are particularly widely used, such as, for example, the Lerner Index (Lerner, 1934), the Herfindal - Hirshman Index (U.S. Department of Justice and the Federal Trade Commission, 2010) or the evaluation of price elasticity (Chamberlin, 1947, 2010). However, the above mentioned methods are either focused on a single economic entity's individual monopoly power measurement or are aimed at a static (single period) data sample analysis, which in either case falls short of a robust approach to medium-term industry-level monopolisation trend evaluation. (Skoruks et al., 2015a) Furthermore, these methods are mutually incompliant and lack integrational synergetic capacities, while individually perfectly fitting their initial purpose and remaining highly useful in terms of unilateral application. (Skoruks et al., 2015b,c).

The previously conducted review of the existing issuerelated scientific literature (Chamberlin, 1947, 2010; Keynes, 2011; Lee, 1955; Robinson, 2012; Samuelson, 1939) and that of the relevant legal texts (Council of the European Union, 2003, 2004; European Commission, 1997, TFEU, 1958, U.S. Department of Justice and the Federal Trade Commission, 2010) had proven the following: it may be stated that a position of full monopoly is the exact opposite of a perfect competition scenario and therefore the conduct of competition in the former case would contradict the relevant process in the latter. The main problem at this point may be defined as factual risk assessment in comparison with those of strictly hypothetically origins: an enterprise, if its actions are left unchecked by the authorised competition situation monitoring public bodies, may first reach a dominant position in the market and, if successful, push for a full economic monopoly through the abuse of its leader status-generated advantages, while the situation of perfect competition is a descriptive model, used for empirical research conduction. Therefore, the process of monopolisation may be described as a tendency or push towards obtaining a de facto full monopoly status by consolidating market power on behalf of the existing competitors and accumulating a necessary amount of the mentioned market power to gain a dominant position in the market in order to create internal barriers for potential new competitor entry blocking. Such process, while generally being lengthy and, in a sense, incremental, commonly occurs under normal economic conditions in contrast to industry-level shock occurrence scenario, in which case the process of monopolisation may accelerate and conduct at a rather swift pace. Consequentially, a quantitative analysis of the researched problem shall require both an empirical model, capable of detecting monopolisation trends under normal economic conditions or, simply put, a situation of consistent yet commensurate economic growth, and a specialised deriving input data levering algorithm. Before elaborating on the above mentioned issue, it would be productive and scientifically rational to outline the used terminology and define the key concepts, employed for the conduction of the current research. (Skoruks et al., 2015a,b,c)

European Union Competition Law in the form of European Commission Regulations and European Court of Justice Decisions, addresses the issue of competition 
enhancement and, counterfactually, the process of monopolisation, defined as market consolidation, via the prism of the relevant market definition as the area of geographical and relevant product market overlapping. (Council of the European Union, 2004)

In order to fully reflect the scope of European practices in competition policy analysis, the following definitions had been officially introduced by the Council of the European Union:

- A relevant product market comprises all the products and/or services which are regarded as interchangeable or substitutable by the consumer by reason of the products' characteristics, their prices and their intended use; (Council of the European Union, 2003)

- A relevant geographic market comprises the physical or digital area in which the enterprises concerned are involved in a remunerated product or services supplying and in which the conditions of competition are sufficiently homogeneous; (Council of the European Union, 2003)

- A relevant market consists of an area in which a particular product or service is sold, alternatively defined as intersection of a relevant product market and a relevant geographic market; (Council of the European Union, 2003)

- A dominant economic position in a relevant market of an undertaking or a group of undertaking occurs there is sufficient capacity to significantly hinder, restrict or distort competition in any relevant market for a sufficient period of time by acting with full or partial independence from competitors, clients, suppliers or consumers. (Council of the European Union, 2003)

An abuse of dominant market position may be manifested as:

- directly or indirectly imposing unfair purchase or selling prices or other unfair trading conditions;

- limiting production, markets or technical development to the prejudice of consumers;

- applying dissimilar conditions to equivalent transactions with other trading parties, thereby placing them at a competitive disadvantage;

- making the conclusion of contracts subject to acceptance by the other parties of supplementary obligations which, by their nature or according to commercial usage, have no connection with the subject of such contracts. (TFEU, 1958)

As it may be deducted from the previously stated information and additionally conducted legal text analysis (Council of the European Union, 2003) the main emphasis in the European Union Competition Law is placed on effective and/or potential competition distortions, which are strictly prohibited as incompliant with the conditions of the Treaty on Functioning of the European Union and the conditionality of the Single Market functioning. (TFEU, 1958) However, it is crucially important to emphasise that even a case of de facto dominant position acquisition by a private for-profit organisation is not a per se violation of the legislation in place - only the proven abuse of such position-generated advantages form a legal basis for public body interference. Therefore, it may be concluded that certain market imperfection are considered by the competent European institutions to be less harmful that direct administrative action-caused distortion of natural economic processes. (Council of the European Union, 2003) Consequentially, a
European context defines the necessity of quantitatively analysing monopolisation trends within any relevant market with a notion of tolerance for minor and, more importantly, economic by their nature competition levering development, to an extent to accepting a dominant market position, obtained via good willed and fair competition, compliant with the rules, regulating the functioning of the Single Market. (Skoruks et al., 2015a)

If addressing monopolisation trend quantitative detection through the prism of market power distribution, concentration and reconfiguration, one must first define the relevant phenomenon and describe its crucial, influence-shaping characteristics. The definition of market power varies among scholars and professionals, being interpreted according to individual commentators' experience, background and affiliation. (OECD, 1993; Council of the European Union, 2004, White, 2012) However, several parallels may be drawn, in particular, regarding market power phenomenon's descriptive features and structural components of its economic essence. The Organization of Economic Cooperation and Development Glossary of Statistical Terms explicitly states that "market power refers to the ability of a firm (or group of firms) to raise and maintain price[s] above the level that would prevail under competition is referred to as market or monopoly power". (OECD, 1993) Simultaneously, several other authors define market power as "the extent to which the firm has discretion over the price that it charges" (White, 2012) and "the ability of a firm to profitably raise the market price of a good or service over marginal cost, granting firms the ability to engage in unilateral anti-competitive behaviour". (Vatiero, 2010) The mentioned definitions, while reflecting on the relevant problematic through the prism of antitrust regulation enforcement, nevertheless provide a robust and useful insight into the economic essence of the addressed phenomenon, leading to an empirical conclusion that market power enables enterprises to grow their presence in the relevant market to an extent which is directly proportionate to the market power volume, corresponding to a certain demand amount, thus allowing unilateral altering of the relevant average price level. (Skoruks et al., 2015b)

Therefore, it may be concluded that market power is present in case of deviations from a unified, industry-wide average price level, which cannot be affected by action of an individual enterprise, thus undermining the distinctive characteristic of a perfect competition market, namely, singularised market level pricing. Consequentially, if prices differ by the suppliers, the next logical step is to differentiate in order to distinguish oneself and enhance market representability, further undermining the notion of perfect competition and, as a result, marginal change-based assessment methods, such as the Lerner index, which are empirically applicable only in cases of absolutely homogeneous products. Furthermore, "the baseline of zero market power is set by the individual firm that produces and sells a homogeneous product". (White, 2012) Therefore, heterogeneous or differentiated product cases are best addressed through implementation of significant market power notion, such position remaining without prejudice to the concept of every enterprise having a certain, if variable in scale and effect, market power and being supplementary to dominant position analysis, as significant market power 
indicates a certain degree of prevalence over the influence of nearest competitors. Robinson (Robinson, 2012) and Chamberlin (Chamberlin, 1947), while taking a marginalism approach, both acknowledged the dispersion of market power, proportionate to the deviation of the perfect competition market structure, dubbing such occurrences as "imperfect competition" and "monopolistic competition" respectfully, arguing that the more imperfect or monopolistic the competition becomes, the more its conjuncture distances itself from the most optimal situation that is perfect competition between homogeneous product vending suppliers.

As argued by various scholars, (Dierker. \& Groda, 1996; Vatiero, 2010; Stucke, 2013), at least a relative market power threshold may be established to evaluate a possible dominant position existence. By going further and taking the next step forward, it might be possible to reach beyond dominant position existence by analysing the competitive structure of the market and concluding the empirical tendency of the mentioned situation emergence. Consequentially, it may be concluded that the currently existing scientific literature provides a solid basis for development of a quantitative analysis of competition structural composition in various heterogeneous product relevant markets and the establishment of a conceptual methodology for the previously mentioned evaluation conduction seems empirically possible. (Skoruks et al., 2015c).

\section{Empirical Concept and Functional Outline of the Developed Methodology}

While taking into account the information, provided in previous sections of the current research, it would be beneficial in terms of enhancing the cumulative objectiveness of the conducted analysis to incorporate the mentioned relevant conditions and influence factors into the structure of the developed methodology, while simultaneously including the effects of external macroeconomic conditions, emerging from the continuous fluctuations and environmental evolution of the international business cycle spiral.

Business cycle maturing and constituent interexchange between the stages of growth and decline may be evaluated in various manners, depending on the preferred analytical practices or the prevalent scholarly paradigms, dominating a certain institutional, organisational or academic environment. (Haugh, 2008; Hansen, 1985; Heijdra, 2009, Kitchin, 1923; Lee, 1955). However, certain methods and techniques had proven to be efficiently robust, while simultaneously remaining flexible in terms of industry level development analysis on a macroeconomic level. (Long \& Plosser, 1983; Romer, 2011, Minsky et al., 1963; Nazarova, 2014). While considering the previously conducted research on business cycle-induced effect incorporation into a unified framework of multifactorial econometrical analysis, (Antonakakis \& Badinger, 2016; Asimakopoulos \& Karavias, 2016; Nazarova \& Dovladbekova, 2015; Wen, 2011) in may be concluded that the dynamics of gross domestic product had been proven to be sufficient in terms of providing a robust insight of the general macroeconomic situation, while simultaneously incorporating many of the area-and industry-specific indicators, therefore the mentioned indicator shall be incorporated into the structure of the developed methodology as an interpretation rage leveraging variable.
Considering both prices and market capacity structural compositions as main and, to a certain extent, fundamental variables, constituting the crucial inputs of the developed methodology, it is imperative to acknowledge that, while focusing on supplier's market power, the most logical perception of the situation would be achieved through the prism of the corresponding demand-side reaction analysis, namely price volatility. As argued by White, if an enterprises' market power is proportionate to its size, the measurement of that very aspect shall deliver a precise answer to the addressed question of monopolisation trend dependence on disproportionate market influence concentration in certain supplier clusters, thus leading to the need of defining an enterprises' size in an analysed relevant market. (White, 2012).

When addressing monopolisation trend quantitative detection through the prism of market share distribution, market power concentration and supply-side reconfiguration, one must first define the relevant phenomenon and describe its crucial, influence-shaping characteristics. Market power enables enterprises to implement unilateral pricing policies in a defined relevant market to an extent which is directly proportionate to the market power volume in their possession, hence the market level medial price level are affected by individual decisions and strategies of those supply-side actors, possessing the necessary amount of influence, while being partially or fully countered by the corresponding reaction of other parties, involved in economic activities within the same relevant market without prejudice to limitation, set by such objective macroeconomic factors as maximal consumption capacity, demand-side response proportionality, decision-making rationality and business cycle corrective effects in terms of implemented pricing policy generated direct profits and indirect costs. Therefore, an analysis of relevant market medial prices seems to be an appropriate method to detect and quantify the presence and future development potential of monopolisation trends.

As argued by various authors (Stucke, 2013; Vatiero, 2010; White, 2012), including Chamberlin (Chamberlin, 1947, 2010) and Robinson (Robinson, 2012), in a situation of perfect competition no enterprise possesses any market power at all, therefore, by applying the same logic as done previously, it may be concluded that the market shares in the mentioned situation should be evenly distributed between the involved suppliers, thus constituting a mutually proportionate involvement in the aggregate supply amount creation. If an enterprise increases its individual supply amount in order to maximize its profit, the marginal revenue ceiling, determined by the constantly fixed, industry level unified price will quickly set a maximum financially profitable individual supply amount, which, ceteris paribus, shall be common for all the involved suppliers. (Skoruks et al., 2015c) Therefore, a situation of perfect competition not only constitutes a completely equal market share distribution, it simultaneously creates a situation of equivalence between the aggregate quantitative measurement of common average market shares and the cumulative individual market power interactional output, resulting in a single, relevant market-level unified price.

Individual supply amount is critically affected by the existing or potential demand amount, with both of the mentioned fundamental economic factors being equalised or, econometrically speaking, mutually balances by the common 
denominator of competitive market price. Therefore, it may be concluded that the effective size of an enterprise, measured by its presence in a market, is determined by the symbiosis of its individual supply amount and the corresponding sale price. Taking the next step forward, it may be deduced that the individual supply amount multiplied by the relevant existing sale price would equal the turnover of the mentioned enterprise over a defined timeframe. Consequentially, it may be concluded that, if an industry level market power distribution analysis is being conducted or the required perspective dictates an evaluation, only focusing on a certain product type or non-supplementary market structures, the turnover of the supply-constituting enterprises seems to be an appropriate parameter for systematic weighting of the implemented prices in order to attribute the nominally dominating pricing trends to the individual market power behind the observed superficial tendencies. Therefore, a market share of an enterprise may be calculated as a ration of its net turnover in a relevant market to the total consumption capability within the same relevant market over a unified time period, the chosen approach being similar to that of the European Commission. (European Commission, 1997)

Consequentially, it may be concluded that a comparison between the average relevant market-level price and the according medial weighted price, calculated, based on involved supply-side actor individual pricing policies and their corresponding market shares, shall deliver an objective and transparent insight of market power distribution within a defined competitive environment. The qualitative interpretation of the acquired quantitative results, however, shall depend heavily on the broader context of current developments in maturing of the relevant business cycle, econometrically reflected by indicating the dynamics of general macroeconomic growth.

Having described the empirical concept of the developed methodology, its functional structure as well as the established analytical framework, it would be scientifically beneficial to further describe the quantitative structure and the correspondingly employed qualitative interpretation principles of the numerical outcomes, generated by the developed methodology.

\section{Quantitative Framework and Econometric Structure of the Developed Methodology}

In order to introduce an scientifically justified index, which objectively reflects the extent and magnitude of individual market power distribution between suppliers, operating within a defined relevant market, and coherently incorporate it into the econometrical structure of the developed methodology, while contemporaneously considering the previously established theoretical basis and adhering to the proposed structural outline, an understanding of market power disproportionate allocation within a relevant market must be quantified in a transparent and comprehensive manner.

While presuming that each enterprise is rationally motivated to exploit the available market power on a largest possible scale and that every enterprise in a competitive environment theoretically engages every other opponent with the synergetic effect of market power being a holistic economic phenomenon, the aggregated disproportionality of market power distribution in a relevant market may be determined as the opposite of simultaneous individual market power cumulative mutual compensation, to be more precise, its excessive amount, which is not being cancelled out by a pro rata competitor influence.

Therefore, allocation of individual market power may be reflected by what for the purpose of the current research shall further be referred to as the market power distribution index (MPDI), which may be calculated in a quantitative fashion, described in Formula 1.

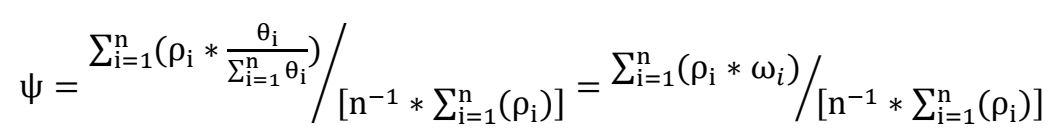

where

$\psi$ - market power distribution index, numerical values;

$\rho \mathrm{i}-$ sales price of a supplier, operating within a defined relevant market, currency units;

$\theta \mathrm{i}-$ net turnover of a supplier, operating within a defined relevant market, currency units;

$\omega \mathrm{i}$ - individual market share of a supplier, operating within a defined relevant market, $\%$;

$\mathrm{n}$ - total number of suppliers, operating within a defined relevant market, numerical values.

The market power distribution index, as any scientifically objective indicator, delivers quantitative outputs that fall under a certain numerical threshold, enabling the corresponding interpretation of the acquired intermediate (in terms of final qualitative general conclusion drawing) results. In order to duly comprehend the magnitude and significance of the detected market power distribution signals and justly attribute them to a presence or absence of monopolisation trend strengthening within a defined relevant market, while avoiding both Type I and Type II errors, the quantitative output value ranges had been assigned qualitative descriptions, reflecting on the specifics of the corresponding economic environment.

As it may be seen from the information, provided in Table 1, market typological stratification is directly rooting from both internal and external influence factors, the former being a reflection of the relevant market's competition environment, assessed through prism the MPDI, while the latter consisting of business cycle-induced macroeconomic conditions, perceived from the perspective of general economic growth. The value ranges of MPDI change in directly-positive correlation with the shifting of macroeconomic environment's development among the stages of the empirical business cycle due to the substantial reconfiguration of competitive situation, driven by external shocks and internal price volatility. 
Market Power Distribution Index: Quantitative Value Ranges and their Corresponding Qualitative Interpretations

\begin{tabular}{|c|c|c|c|c|}
\hline$\Delta$ GDP, $\%$ & MPDI value range & Competition type & Market power distribution & Monopolisation risk \\
\hline \multirow{5}{*}{$(-\infty ;-1.49)$} & {$[0 ; 0.93)$} & Overextended & Divergent & Moderate \\
\hline & {$[0.93 ; 1)$} & Differentiated & Homogeneous & Low \\
\hline & [1] & Equilibrium & Optimal & Absent \\
\hline & $(1 ; 1.11]$ & Cross-niche & Heterogeneous & Low \\
\hline & $(1.11 ; \infty)$ & Oligopolistic & Dominating & High \\
\hline \multirow{5}{*}[-1.49;1.89]{} & {$[0 ; 0,83)$} & Overextended & Divergent & Moderate \\
\hline & {$[0.83 ; 1)$} & Differentiated & Homogeneous & Low \\
\hline & [1] & Equilibrium & Optimal & Absent \\
\hline & $(1 ; 1.19]$ & Cross - niche & Heterogeneous & Low \\
\hline & $(1.19 ; \infty)$ & Oligopolistic & Dominating & High \\
\hline \multirow{5}{*}{$(1.89 ; \infty)$} & {$[0 ; 0.77)$} & Overextended & Divergent & Moderate \\
\hline & {$[0.77 ; 1)$} & Differentiated & Homogeneous & Low \\
\hline & {$[1]$} & Equilibrium & Optimal & Absent \\
\hline & $(1 ; 1.25]$ & Cross - niche & Heterogeneous & Low \\
\hline & $(1.25 ; \infty)$ & Oligopolistic & Dominating & High \\
\hline
\end{tabular}

Following the logic of esteemed modern day scholars (Daude et al., 2016; Minsky et al., 1963; White, 2012) and the empirical acknowledgments of such titans of economic thought as Johan Robinson (Robinson, 2012), J. M. Keynes (Keynes, 2011) and Jean Tirole (Tirole, 1988) market entry barriers, financial resource availability and other entrepreneurial decision-making influencing economic factors are based on profitability margin concerns and risk awareness, which is why an economic downslide significantly decreases external competitive pressure and intensifies internal market power consolidation efforts. Consequentially, MPDI quantitative value ranges need to objectively reflect the mentioned processes, which is the reason behind their limit expansion in a situation of economic growth and their inevitable narrowing in cases of recession.

Monopolisation risks are dependant of the corresponding market power distribution type, being proportionately lower, when MPDI value is closer to 1 , which reflects a complete absence of disproportionality in the distribution of market power within a defined relevant market. However, such situation of perfect competition is highly unlikely to emerge in practice due to, in particular, while not solely dependent on, the differentiation strategies and other promotion practices, implemented by the suppliers, which are active in a defined relevant market. Close proximity to MPDI value of 1 indicates a "healthy" and productive state of competition and poses little no none medium-term monopolisation risks.

Both homogeneous and heterogeneous market power distribution indicates monopolistic competition environments, the former indicating a higher degree of countervailing clientele power, observable in cases of classic economic bellum omnium contra omnes, while the latter reflecting a more or less cross-niche differentiated monopolistic competition scenario development.

Monopolistic market power distribution, on the other hand, suggests a high probability of an achieved dominant market position, which, while in the context of European Union Competition Law not being a legal infringement per se, nevertheless poses significant negative future development risks and indicates a strong basis for at least a regulatory market inquire or an in-depth evaluation of the situation in order to justly assess the possible progression of excessive individual market power concentration within a single supply-side economic cluster.

Divergent market power concentration poses long-term monopolisation risks as it indicates a highly fragmented supply structure, both vulnerable to external shocks and internally unsustainable due to low if any profit margins. The mentioned fragmentation disables the suppliers to accumulate sufficient financial reserves or attract the necessary external funding, which, combined with occasional slipping into loss generation, may trigger swift and disproportional marketlevel consolidation, launching those market actors, who managed to remain engaged in economic activities, into an oligopoly position or, in particularly extreme cases, even a quasi-monopolistic market structure. In other words, divergent market power distribution has the objectionable quality of shifting to a state of monopolistic conjuncture at a rather swift pace, which consequentially leads to a logical conclusion of such situation being dubbed as risky and requesting additional monitoring attention on behalf of the competent regulatory authorities.

As it may be consequentially deducted, MPDI reflects both the specifics of the analysed relevant market's conjuncture structure and the state of competition within the corresponding economic environment, contextualised within the conduct of the empirical business cycle maturing, thus enabling a multi-scale assessment of business processes, comprising the mentioned economic environment, from a dual, private and public actor, perspective. Market entry attractiveness for the former and the analysis of the existing competition environment in the context of established competition policy enforcement for the latter, enabled by the developed methodology, allows the conducted research to be found empirically relevant for addressing topical issues of modern economic theory and positively enhancing the existing scientific literature on studies of the phenomenon of monopolisation as well as functionally beneficial in terms of it practical future implementation opportunities.

\section{Conclusions}

Taking into account the conducted analysis, the acquired quantitative results and the corresponding qualitative findings on the defined research topic, the following may be concluded: 
- The process of monopolisation is a natural economic phenomenon, emerging from and simulated by competing enterprise strive for business process profitability, market position strengthening and gaining the desired entrepreneurial competitive advantages;

- Monopolisation trends are most likely to emerge in situations of disproportionate individual market power distribution between supply-side market actors, engaged in economic activities within a defined relevant market and mutually competing, while implementing price-related engagement strategies;

- A bibliographical analysis of the exiting scientific literature, legal texts and the quantitative results of the previously conducted as well as the current research had positively verified that, empirically, monopolisation trends may be detected by multi-factorial (in terms of economic output measurement, for example, expressed as GDP dynamics) evaluation of individual market power distribution conjuncture through the prism of price level comparative analysis;

- $\quad$ Therefore, the research hypothesis may be held as confirmed: monopolisation trends in modern open market economies are indeed driven by excessive individual market power concentration, hence they may be detected and quantitatively measured by evaluating the relevant competition environment through price level analysis, while the possible differences in generated quantitative results qualitative interpretations are strongly dependant on the existing macroeconomic conditions, which may be successfully addressed by assessing the current development stage of the empirical business cycle;

- Hence, applying harmonised quantitative analytical methods and their qualitative interpretation algorithms in the context of synergetic econometric modelling proved to be an efficient methodological approach, suited for monopolisation trend detection, decoding and evaluation;

- The introduced methodology is an example of multifactorial empirical econometrical analysis and therefore has further development potential in terms of its reconfiguration and recalibration to suit the conditions and the individual specifics of distinct relevant markets, furthermore, the mentioned productive adaptation of the developed empirical methodology constitutes a considerable research interest and shall be regarded as a topic for further exploratory investigation.

\section{References}

Antonakakis, N., \& Badinger, H. (2016). Economic Growth, Volatility, and Cross-Country Spillovers: New Evidence for the G7 Countries. Economic modelling, 52(1), 352-365. https://doi.org/10.1016/j.econmod.2015.08.035

Asimakopoulos, S., \& Karavias, Y. (2016). The Impact of Government Size on Economic Growth: A Threshold Analysis. Economic Letters, 139(1), 65-68. https://doi.org/10.1016/j.econlet.2015.12.010

Chamberlin, E. H. (1947). The Theory of Monopolistic Competition: Fifth Edition. Cambridge: Harvard University Press. pp. 30-217.

Chamberlin, E. H. (2010). On the Origin of Oligopoly: Reediting. Cambridge: Cambridge University Press. pp. $113-149$.

Council of the European Union (2003). Council Regulation (EC) No 1/2003 of 16 December 2002 on the Implementation of the Rules on Competition Laid Down in Articles 81 and 82 of the Treaty. Official Journal of the European Communities, 5-13. http://eur-lex.europa.eu/legal-content/EN/TXT/PDF/?uri=CELEX:32003R0001\&from=EN.

Council of the European Union. (2004). Council Regulation (EC) No 139/2004 of 20 January 2004 on the Control of Concentrations Between Undertakings. Official Journal of the European Communities, 1-22. http://eurlex.europa.eu/legal-content/EN/TXT/PDF/?uri=CELEX:32004R0139\&from=EN.

Daude, C., Nagengast, A., \& Perea, J. R. (2016). Productive Capabilities: An Empirical Analysis of Their Drivers. The Journal of International Trade \& Economic Development. 25(4), 504-535. https://doi.org/10.1080/09638 199.2015.1073342

Dierker, E., \& Grodal, B. (1996). Profit Maximization Mitigates Competition. Economic Theory, Springer - Verlag, 7(1), 139-160. https://doi.org/10.1007/BF01212187

European Commission (1997). Commission Notice on the Definition of Relevant Market for the Purposes of Community Competition Law. Official Journal of the European Communities, 5-13. http://eur-lex.europa.eu/legalcontent/EN/TXT/PDF/?uri=CELEX:31997Y1209\%2801\%29\&from=EN.

Hansen, G. D. (1985). Indivisible Labor and the Business Cycle. Journal of Monetary Economics, 16(3), $309-327$. https://doi.org/10.1016/0304-3932(85)90039-X

Haugh, D. L. (2008). Monetary Policy under Uncertainty about the Nature of Asset-Price Shocks. International Journal of Central banking, 4(4), 39-83. ISSN: 1815-4654.

Heijdra, B. (2009). Real Business Cycles. Foundations of Modern Macroeconomics (2nd ed.). Oxford: Oxford University Press. pp. 495-552.

Keynes, J. M. (2011). The General Theory of Employment, Interest and Money. London: Macmillan. pp. $289-315$.

Kitchin, J. (1923). Cycles and Trends in Economic Factors. Review of Economics and Statistics, MIT Press, 5(1), $10-16$. https://doi.org/10.2307/1927031

Lee, M. W. (1955). Economic Fluctuations. Homewood, IL: Richard D. Irwin, pp. 2-25.

Lerner, A. P. (1934). The Concept of Monopoly and the Measurement of Monopoly Power. The Review of Economic Studies, Oxford University Press, 1(3), 157-175. https://doi.org/10.2307/2967480 
Maija Senfelde, Dmitrijs Skoruks, Jekaterina Nazarova. Multifactorial Assessment of Monopolisation Trends through the...

Long, J. Jr., \& Plosser, Ch. (1983). Real Business Cycles. Journal of Political Economy, 91(1), 39-69. https://doi.org/10.1086/261128

Minsky, H. P., Okun A. M., \& Warburton, C. (1963). Comments on Friedman's and Schwartz' Money and the Business Cycles. The Review of Economics and Statistics. MIT Press, 45(1), 64-78. https://doi.org/10.2307/1927149

Nazarova, J. \& Dovladbekova, I. (2015). Investment Planning in the Context of Volatile Business Cycles. Economic Science for Rural Development, 37(1),180-189. ISBN: 978-9984-48-187-6

Nazarova, J. (2014). Portfolio Structure Planning and Its Future Price Forecasting Model. Business and ManagementSpausdinta, 1(1), 290-297. https://doi.org/10.3846/bm.2014.036

Organisation for Economic Cooperation and Development (OECD), Directorate for Financial, Fiscal and Enterprise Affairs (1993). Glossary of Industrial Organisation Economics and Competition Law. Paris, pp. 57. http://www.oecd.org/regreform/sectors/2376087.pdf.

Plosser, C. (1989). Understanding Real Business Cycles. Journal of Economic Perspectives, 3(1), 51-77. https://doi.org/10. 1257/jep.3.3.51

Robinson, J. (2012). The Economics of Imperfect Competition: 1969-2012 Anthology Edition. London: Macmillan. pp. 189-211.

Romer, D. (2011). Real-Business-Cycle Theory. Advanced Macroeconomics (Fourth edition). New York: McGraw-Hill. pp. 189-237.

Samuelson, P. A. (1939). Interactions Between the Multiplier Analysis and the Principle of Acceleration. Review of Economic Statistics, MIT Pres, 21(1), 75-78. https://doi.org/10.2307/1927758

Skoruks, D., Nazarova, J., \& Senfelde, M. (2015a). Countervailing Market Power Analysis: an Assessment of Monopolisation Tendencies in Modern Business Environment. Sciemcee Publishing: Proceedings of the 4th Biannual CER Comparative European Research Conference, 2(2), 67-71. ISBN: 978-0-9928772-8-6

Skoruks D., Nazarova J., \& Senfelde, M. (2015b). Evaluating Monopolisation Tendencies through Quantitative Analysis of Market Power Distribution. MMK 2015: International Masaryk Conference for Ph.D. Students and Young Researchers, Magnanimitas, 614-623. ISBN 978-80-87952-12-2

Skoruks, D., Nazarova, J., \& Senfelde, M. (2015c). Monopolistic Trend Analysis in the Context of Efficient Entrepreneurial Decision Making. Journal of System and Management Sciences, 5(2), 33-58. ISSN: 1816-6075.

Skoruks, D., \& Senfelde, M. (2015). The Empirical Methodology of Modern Monopolization Process Assessment as a Sustainable Consumption Insurance Tool. Economic Science for Rural Development, 40(1), 14-46. ISBN: 978-998448-190-6.

Skoruks, D. (2014). Complex Econometric Model of Monopolisation Process Evaluation. Procedia - Social and Behavioral Sciences, 110(1), 202-214. https://doi.org/10.1016/j.sbspro.2013.12.863

Smith, A. (2007). An Inquiry into the Nature and Causes of the Wealth of Nations. Books I, II, III, IV and V. Lausanne: MetaLibri. pp. 347-351.

Stucke, M. E (2013). Is Competition Always Good? Oxford Journal of Antitrust Enforcement, 1(1),162-197. https://doi.org/10.1093/jaenfo/jns008

Tirole, J. (1988). The Theory of Industrial Organisation. New Delhi: PHI Learning Pvt. Ltd, pp. 63-91.

Treaty on the Functioning of the European Union (TFEU) [Consolidated version] (1958). Rome, pp. 88 - 89. http://eurlex.europa.eu/legal-content/EN/TXT/PDF/?uri=CELEX:12012E/TXT\&from=EN.

U.S. Department of Justice and the Federal Trade Commission. (2010). Horizontal Merger Guidelines. Washington, D.C. pp. 16-19. http://www.justice.gov/atr/public/guidelines/hmg-2010.html\#5b.

Vatiero, M. (2010) The Ordoliberal Notion of Market Power: an Institutionalist Reassessment. European Competition Journal, 6(3), 689-707. https://doi.org/10.5235/ecj.v6n3.689

Wen, Y. (2011). Understanding Self-Fulfilling Rational Expectations Equilibria in Real Business Cycle Models. Journal of Economic Dynamics and Control - Elsevier, 25(8), 1221-1240. https://doi.org/10.1016/S0165-1889(99)00054-8

White, L. (2012). Market Power: How Does It Arise? How Is It Measured? New York: New York University, Leonard N. Stern School of Business, Department of Economics, Working papers, EC-1206.http://webdocs.stern.nyu.edu/old_web/economics/docs/workingpapers/2012/White_MarketPowerRiseandMeasure. pdf.

The article has been reviewed.

Received in May, 2016; accepted in November, 2016 